\title{
EFFECTS OF POROSITY ON ULTRASONIC CHARACTERISTIC PARAMETERS AND MECHANICAL PROPERTIES OF GLASS FIBER REINFORCED COMPOSITES
}

\author{
Wen Ma \\ School of Material of Science and Engineering, Beihang University, Xueyuan Road 37, Haidian District, \\ Beijing, 100191, China \\ vineymawen@gmail.com \\ Fushun Liu \\ school of Material of Science and Engineering, Beihang University, Xueyuan Road 37, Haidian District, \\ Beijing, 100191, China \\ liufs@buaa.edu.cn
}

\begin{abstract}
Voids are inevitable in the fabrication of fiber reinforced composites and have a detrimental impact on mechanical properties of composites. Different void contents were acquired by applying different vacuum bag pressures. Ultrasonic inspection and ablation density method were adopted to measure the ultrasonic characteristic parameters and average porosity, the characterization of voids' distribution, shape and size were carried out through metallographic analysis. Effects of void content on the tensile, flexural and interlaminar shear properties and the ultrasonic characteristic parameters were discussed. The results showed that, as vacuum bag pressure went from $-50 \mathrm{kPa}$ to $-98 \mathrm{kPa}$, the voids content decreased from 4.36 to 0.34 , the ultrasonic attenuation coefficient decreased, but the mechanical strengths all increased.
\end{abstract}

Keywords: Glass fiber reinforced plastic (GFRP); Porosity; Ultrasonic inspection; Ultrasonic characteristic parameters; Mechanical properties.

\section{Introduction}

Voids are one of the most common types of manufacturing process induced defects in fiber reinforced composites. They are formed primarily due to the following two reasons $^{[1]}$ : one is that fiber is not infiltrated fully, and then the mechanical air entrapment will form voids. Volatile substance during curing process (like the volatilization of exposy) is the other reason induced voids. The effect of voids on the mechanical properties of fiber reinforced composites has been widely studied. Voids have detrimental impact mainly on the longitudinal and transverse tensile properties, flexural performance, interlaminar shear strength (ILSS), compression properties ${ }^{[2 \sim 3,7 \sim 9]}$ as well as impact properties and fatigue performance ${ }^{[4]}$. Judd et al presented ILSS dropped 7\% with $1 \%$ increasing porosity when void content is less than $4 \%$. At present, wind turbine blade, mainly made of glass fiber composites, chronically resists formidable wind load, gas 
flush and other environment effects ${ }^{[5]}$. The voids may become the crack source Gradually ${ }^{[6]}$. Therefore, the study on the void of glass fiber reinforced composites applying in wind turbine blade is very essential.

Ultrasonic inspection is the most used nondestructive technique in composites. The pore defect will weaken ultrasonic wave and affect sound velocity and acoustic impedance in composites. Therefore, it is feasible to evaluate the porosity by establishing the relationship between ultrasonic characteristic parameters and void content.

In related literatures, the studies were focused on the effect of voids on mechanical properties of carbon fiber reinforced composites used in aerospace field. In this paper, various vacuum bag pressures were applied to fabricate glass fiber reinforced laminates with varying void contents. The micro characteristics of voids, the effect of porosity on ultrasonic characteristic parameters and mechanical properties were studied.

\section{Experimental procedures}

\subsection{Fabrication of laminates of glass fiber reinforced plastic}

The laminates of GFRP were produced using a vacuum bag molding process with EKT750, three axial $(0 /-45 /+45)$ glass fiber cloth. The initial fiber volume fraction $V_{f}$ of composite laminates was $65 \% \pm 2$. The fiber and uncured resin densities are also known. The composite laminates were manually layered with seven layers. Three rectangular plates of $320 \mathrm{~mm} \times 250 \mathrm{~mm}$ were fabricated, with colloidal injection temperature $40^{\circ} \mathrm{C}$ and vacuum bag pressures of $-50 \mathrm{kPa},-90 \mathrm{kPa}$ and $-98 \mathrm{kPa}$ respectively.

\subsection{C-scan ultrasonic inspection}

All the laminates were inspected using water immersion ultrasonic C-scan to identify areas of constant porosity lever and calculate ultrasonic characteristic parameters. The scanning was carried out using one pulse reflecting technique. The parameters of focusing probe using in the scanning: $2.25 \mathrm{M}$ frequency, 1.9 inch focal length. The size ratio of scanning images and specimen was $1: 1$.

\subsection{Metallographic microstructure analysis}

For each composite laminate, two specimens of $15 \mathrm{~mm} \times 15 \mathrm{~mm}$ were cut parallel to the ply direction for image analysis. According to a Chinese standard (GB 3365-82), the sample for image analysis were embedded in an epoxy resin and carefully polished with 500, 800, 1200 and 1500 grit size silicon carbide abrasive paper. Then, the samples were finished with $1.5 \mu \mathrm{m}$ diamond paste and ultrasonic cleaning. The polished surfaces were observed using an optical microscope (OLYMPUS BX51M). The distribution, size and shape of voids in images were analyzed by using image analysis software. 


\subsection{Assessment of void content}

According to the $\mathrm{C}$-scan inspection, five specimens were cut from each plates. Their densities (GB/T 1463-2005) and mass fractions of resin (GB/T 2577-2005) were determined to estimate the void content. The average void content of laminates was measured by ablation density method, the calculated formula is as follows:

$$
P_{v}(\%)=100-r_{c}\left(\frac{w_{r}}{r_{r}}+\frac{w_{f}}{r_{f}}\right)
$$

Where $P_{v}(\%)$ is the porosity, $\rho_{c}$ is the density of specimen, $w_{r}$ and $w_{f}$ are mass fraction of resin and fiber respectively, $\rho_{r}$ and $\rho_{f}$ are density of resin and fiber respectively.

\subsection{Mechanical testing}

To assess the effect of voids on the mechanical properties of the laminates, tensile (GB/T 1447-2005), flexural (GB/T 1449-2005) and interlaminar shear (ASTM D2344) testing were used for mechanical evaluation. Tensile strength and modulus, flexural strength and modulus and interlaminar shear strength (ILSS) were measured in the INSTRON performance testing machine. Each test included five specimens.

\section{Results and Discussion}

\subsection{Microstructure analysis}

Fig.1 shows a typical photomicrograph of all the three laminates. As can be seen from figure 1 , the void content in $-98 \mathrm{kPa}$ laminate is much smaller than that in-50kPa laminate. In the vacuum bag curing process with colloidal injection temperature $40 \mathrm{C}^{\circ}$, the entrapped air is the main source of voids. Most of large voids locate in resin surplus area and ply interface where entrapped air can not be expelled fully, but small voids mainly distribute in fiber area where fiber can not be infiltrated. In these figures, the voids are shown as holes and most of them are spherical or ellipsoidal.

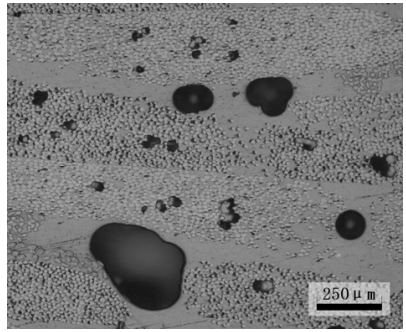

(a) $-50 \mathrm{kPa}(100 \times)$

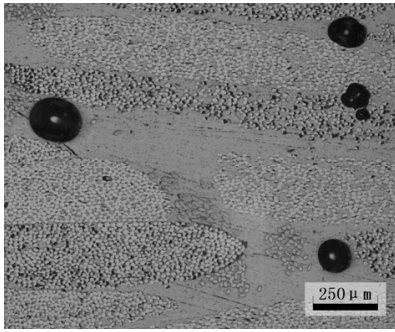

(b) $-90 \mathrm{kPa}(100 \times)$

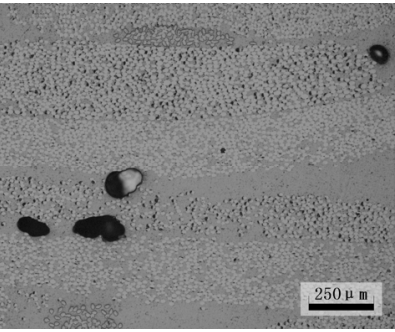

(c) $-98 \mathrm{kPa}(10 \times)$

Fig. 1. Micrographs at $-50 \mathrm{kPa}, 90 \mathrm{kPa}$ and $-98 \mathrm{kPa}$ 


\subsection{Effect of vacuum bag pressures on the void content}

Table 1 shows the measurement of the average void content at different vacuum bag pressures. As can be seen, the void content increases from $0.31 \%$ to $4.36 \%$ as the vacuum bag pressure goes from $-98 \mathrm{kPa}$ to $-50 \mathrm{kPa}$. The reason is the smaller relative vacuum is, the less entrapped air is. Consequently, pores can be prevented from forming and growing effectively with greater compacted pressure.

Table 1. Measurement of porosity, mechanical properties and ultrasonic characteristic coefficient.

\begin{tabular}{|c|c|c|c|c|c|c|c|c|c|}
\hline Vacuum & Void & Tensile & Tensile & Flexural & Flexural & ILSS & Sound & Acoustic & Attenuation \\
\hline $\begin{array}{l}\text { Pressure } \\
/ \mathrm{kPa}\end{array}$ & $\begin{array}{l}\text { Content } \\
1 \%\end{array}$ & $\begin{array}{l}\text { Strength } \\
/ \mathrm{Mpa}\end{array}$ & $\begin{array}{l}\text { Modulus } \\
\text { /GPa } \\
\end{array}$ & $\begin{array}{l}\text { Strength } \\
\text { /Mpa }\end{array}$ & $\begin{array}{l}\text { Modulus } \\
/ \mathrm{GPa}\end{array}$ & /MPa & $\begin{array}{l}\text { Velocity } \\
v / \text { m.s- } 1\end{array}$ & $\begin{array}{l}\text { Impedance } \\
Z Z_{c}\end{array}$ & $\begin{array}{c}\text { Coefficient } \\
\alpha / \mathrm{dB} . \mathrm{mm}-1 \\
\end{array}$ \\
\hline-50 & 4.36 & 136.02 & 11.79 & 227.94 & 9.11 & 26.43 & 3125 & 5625.0 & 1.96 \\
\hline-90 & 0.94 & 143.70 & 13.65 & 249.83 & 10.74 & 27.89 & 3223 & 6046.3 & 1.83 \\
\hline-98 & 0.31 & 146.76 & 14.52 & 260.05 & 11.22 & 28.14 & 3276 & 6217.8 & 1.73 \\
\hline
\end{tabular}

\subsection{Effect of void content on mechanical properties}

Table 1 shows the effect of vacuum bag pressure on void content is significant. And in turn the void content influences the mechanical performances of laminates. Fig.2 (a) and fig.2 (b) shows the measured tensile, flexural and ILSS strengths and moduli. As is shown both the strengths and moduli decrease with increasing void content. However, the drop-off rate is different. The decreasing percentage for flexural strength is the largest, and the tensile modulus almost has the same declined percentage as the flexural modulus.

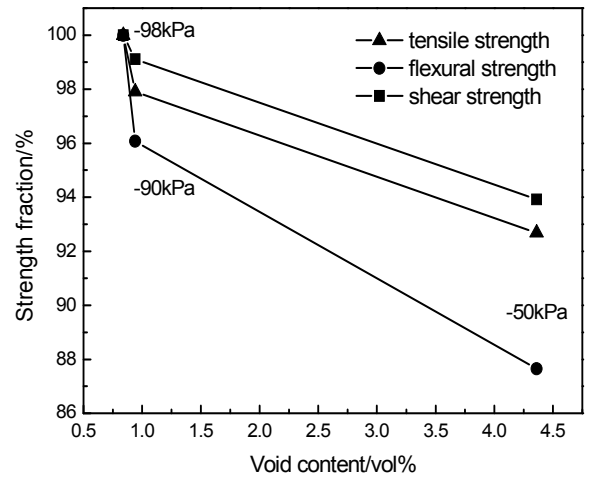

(a)

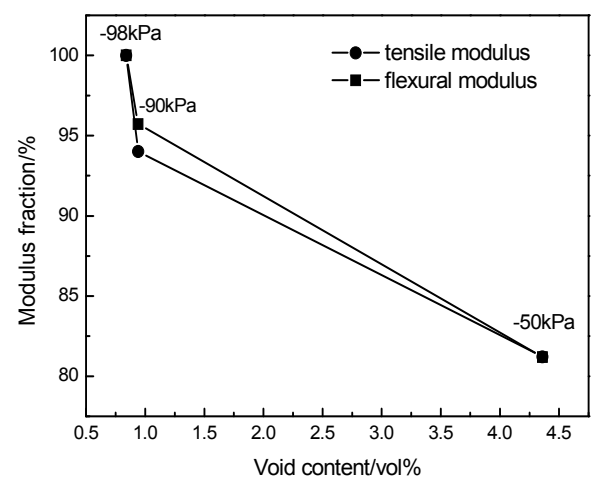

(b)

Fig. 2. Relationship between strengths (a)/ moduli (b) and void content

\subsection{Analysis of ultrasonic inspection}

Fig.3 shows a C-scan image of the laminate with vacuum bag pressure $-90 \mathrm{kPa}$, which includes information of A, B and C scan. As can be seen from the C-scan image, the pores in the laminate distribute uniformly. So the specimens for the measurement of porosity and mechanical performances can represent the whole laminate. 


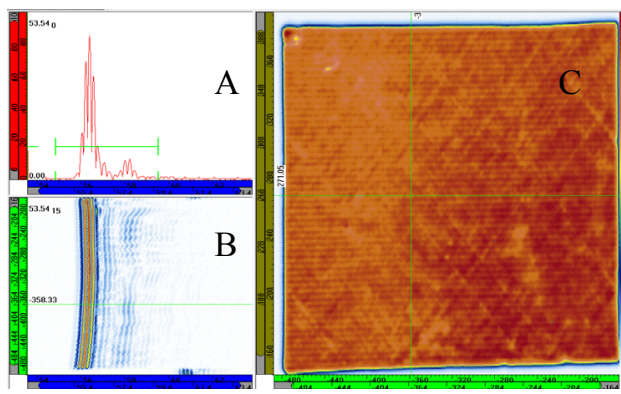

Fig. 3. Ultrasonic testing picture with relative vacuum $-90 \mathrm{kPa}$

In the one pulse reflecting testing, the relationship inferred between the attenuation coefficient $a$ and attenuation of ultrasonic amplitude $\mathrm{A}_{\mathrm{T}}$ is as follows:

$$
\alpha=\frac{10}{d_{c}} \times\left[\lg \left(1-R^{2}\right)+A_{T}\right]
$$

Where $d_{c}$ is the thickness of the plate, $R$ is the reflecting coefficient of the plate, $A_{T}$ is attenuation of ultrasonic amplitude $(\mathrm{dB} / \mathrm{mm})$.

Table 1 gives the mean ultrasonic velocity, acoustic impedance and attenuation coefficient of laminates at different vacuum bag pressures. As expected larger ultrasonic velocity and acoustic impedance as well as smaller attenuation coefficient correspond to lower porosity laminates, which is shown in table 1. Fig.4 presents the relationship between the ultrasonic characteristic parameters and void content. In the ultrasonic nondestructive testing of composites, the variation of porosity will cause the variation of ultrasonic velocity, acoustic impedance and attenuation coefficient. Therefore, ultrasonic characteristic can be used to characterize the magnitude of the porosity.

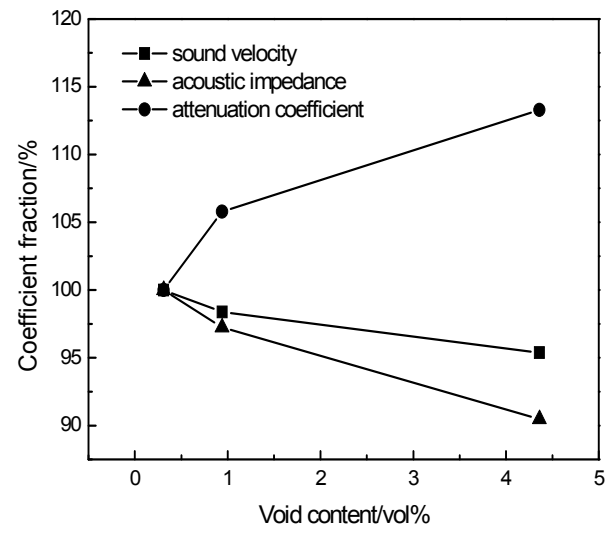

Fig. 4. Relationship between porosity and ultrasonic characteristic parameters

In previous studies ${ }^{[11,12]}$, sound velocity and acoustic impedance were applied to evaluate the void content but it was not very successful. At present, ultrasonic attenuation 
technique is the most widely used method for the nondestructive testing of porosity. Liu Ling et al ${ }^{[9]}$ have studied the effect of void content on ultrasonic attenuation coefficient and mechanical properties of carbon fiber composites, the result of which was: the attenuation coefficient decreased, ILSS, flexural and tensile strengths increased with decreasing porosity. In this study, attenuation coefficient decreases from $1.96 \mathrm{~dB} / \mathrm{mm}$ to $1.73 \mathrm{~dB} / \mathrm{mm}$ as void content increases from 0.31 to 4.36 . The changing trend between attenuation coefficient and porosity has a good correspondence with previous studies.

\section{Conclusions}

Glass fiber composite laminates fabricated by different vacuum bag pressures $(-98 \mathrm{kPa},-90 \mathrm{kPa},-50 \mathrm{kPa})$ presented various void contents from $0.31 \%$ to $4.36 \%$. Mechanical properties showed decreasing trends, ultrasonic attenuation coefficient showed an increasing trend from $1.96 \mathrm{~dB} / \mathrm{mm}$ to $1.73 \mathrm{~dB} / \mathrm{mm}$ with increasing void content. The research objection of this study is glass fiber composites laminate. The changing trends between mechanical properties or ultrasonic characteristic parameters and porosity had a good correspondence with previous studies. Therefore, the basic research model of carbon fiber composites can be used to study the void content of glass fiber composites.

\section{References}

1. Zhang Ligong, Zhang Zuoguang, Analysis of defects in advanced composites, FRP, 2001(2), p. 41-45.

2. N. C. W. Judd, W. W. Wright, Voids and their effects on the mechanical properties of composites - an appraisal, in SAMPLE Journal, 1978, January/ February, p. 10-14.

3. Tang J M, Lee I W, Springer G S, Effects of cure pressure on resin flow, voids, and mechanical properties in J Comp Mater, 1987, 21(11), p. 421-440.

4. A. R. Chambers et al, The effect of voids on the flexural fatigue performance of unidirectional carbon fiber composites developed for wind turbine applications, International Journal of Fatigue, 2006, 28, p. 1389-1398.

5. Feng Xiaobing, Wang Wei, Materials and process research of $2 \mathrm{M}$ egawatt wind turbine blade, FRP, 2010(7), p. 84-88.

6. Hongyan Zhu et al, Influence of Voids on the Tensile Performance of Carbon/ epoxy Fabric Laminates, J. Mater. Sci. Technol., 2011, 27(1), p. 69-73.

7. Zhu Hongyan et al, Effect of curing pressure on voids and mechanical properties of carbon fiber reinforced composite laminate, Journal of Solid Rocket Technology, 2009, 6(32) , p. 694-697.

8. Ling Liu et al, Effects of cure cycles on void content and mechanical properties of composite laminates, Composite Structures, 2006, 73, p. 303-309.

9. Liu Ling et al, Effects of porosity on the ultrasonic absorption coefficient and mechanical strength of carbon epoxy composites, Acta material composite sinica, 2004, 5(21) , p. 116121.

10. Almeida S F M, Nogueira Neto Z S, Effects of void content on the strength of composite laminates, Comp Struck, 1994, 28(8), p. 139-148.

11. Stone D E, Clarke B, Ultrasonic attenuation as a measure of void content in carbon fiber reinforced plastics, $N D T, 1975,8(3)$, p. 137 145.

12. Lin $\mathrm{Li}$ et al, Ultrasonic determination of carbon fiber composite porosity using acoustic impedance, Acta Material Composite Sinica, 2009(6), 3(26) , p.105-110. 